\title{
Transmission Electron Microscopy and X-ray Photoelectron Spectroscopy Studies of Soot Particles Emitted from a Domestic Cook-stove
}

\author{
Giovanni Carabali ${ }^{1}$, Telma Castro ${ }^{2}$, Oscar Peralta $^{2}$ and Luisa Molina ${ }^{3,4}$ \\ ${ }^{1 .}$ Instituto de Geofísica, Universidad Nacional Autónoma de México, Mexico City, México. \\ 2. Centro de Ciencias de la Atmosfera, Universidad Nacional Autónoma de México. Mexico City, \\ México. \\ 3. Molina Center for Energy and the Environment, La Jolla, CA, USA \\ 4. Massachusetts Institute of Technology, Cambridge, MA, USA
}

Household air pollution due to the use of biomass fuels in domestic cook stoves is a serious public health problem. It is estimated that two billion people use biomass fuel (wood, dung and fiber residues) as their primary energy source for domestic needs such as heating and cooking [1]. People who use these tools for food preparation are exposed to different kind of emissions, mainly soot originated by the inefficient combustion. Inhalation of soot causing serious adverse health effects in women and children, for this reason it is important to learn more about the nature of these particles. [2], [3], [4].

The main goal of this study is to characterize soot particles emitted by wood burning cook stoves. A microstructure and morphology study of soot was carried out with high-resolution transmission electron microscopy (HRTEM). The chemical composition on surface and carbon bonding is explored with Xray photoelectron spectra (XPS) of soot samples deposited directly over aluminum foils.

In order to sample freshly emitted soot particles, an eight stage Micro-Orifice Uniform Cascade Impactor (MOUDI) (size-selective aerosol sampler) was used. Particles were collected onto 200 Gilder mesh grids from Ted Pella (TEM-grids, LF-200-Cu) coated with a thin film of collodion polymer [5]. TEM-grids were fixed on the aluminum foil by using a double-sided adhesive carbon tape and finally were placed in the last MOUDI stage $\left(d_{50}=0.18 \mu \mathrm{m}\right)$. In this study, TEM images we obtained by using a JEOL HRTEM 4000EX microscope of $0.17 \mathrm{~nm}$ point-to-point resolution, operated at $400 \mathrm{KV}$. XPS spectra were obtained with a system equipped with an electron energy analyzer model Phoibos 150 , an electron gun and a dual anode X-ray source from SPECS.

The analysis of TEM micrographs in figure 1 shows soot particles with complex morphologies (aggregates) that result from collisions between primary nano-sized particles. Figure $2 \mathrm{a}, \mathrm{b}$ and $\mathrm{c}$ show HRTEM images at high magnifications. In this study, the vast majority of primary particles present an amorphous layer with a core-shell structure (fig. 2c). In other hand, XPS survey scan in figure $2 \mathrm{~d}$ shows that particles are mainly composed by carbon and oxygen. Additionally, the XPS C-1s spectra in figure 2e show carbon with three peaks corresponding to $\mathrm{sp}^{2}, \mathrm{sp}^{3}$ hybridization and carbon oxygen bond.

References:

[1] T. Bond and R. Bergstrom, Aerosol Sci Tech 39 (2005), p.1.

[2] World Health Organization (WHO). (1997). Health and environment in sustainable development:

five years after the earth summit. Geneva: WHO/EHG/97.8.

[3] C.A. Pope III and D.W. Dockery, J Air Waste Manag Assoc, 56 (2006), p.709.

[4] O.B. Popovitcheva et al, Phys Chem Chem Phys, 2, (2000), p.4421. 
[5] G. Carabali, et al, Atmos. Chem. Phys.12 (2012), p.2747.

[6] This study was supported by the Molina Center for Energy and the Environment under UNEP Contract GFL-4C58. We acknowledge partial support from CONACyT and DGAPA-UNAM, Mexican agencies.

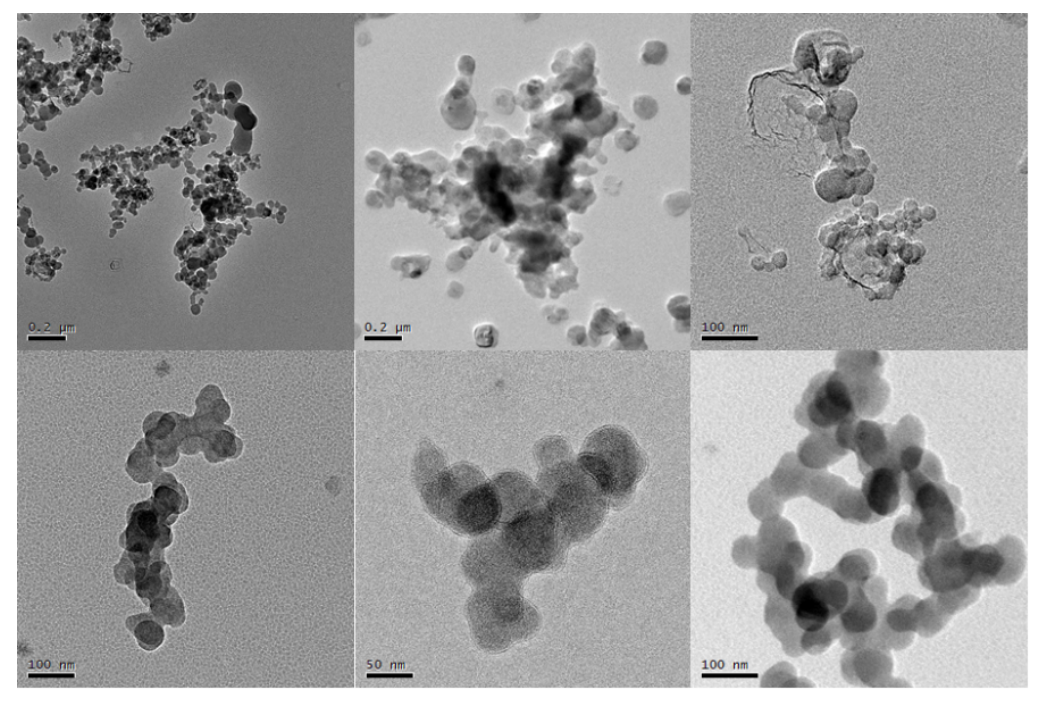

Figure 1. TEM images of soot particles sampled directly from a wood burning cook-stove.
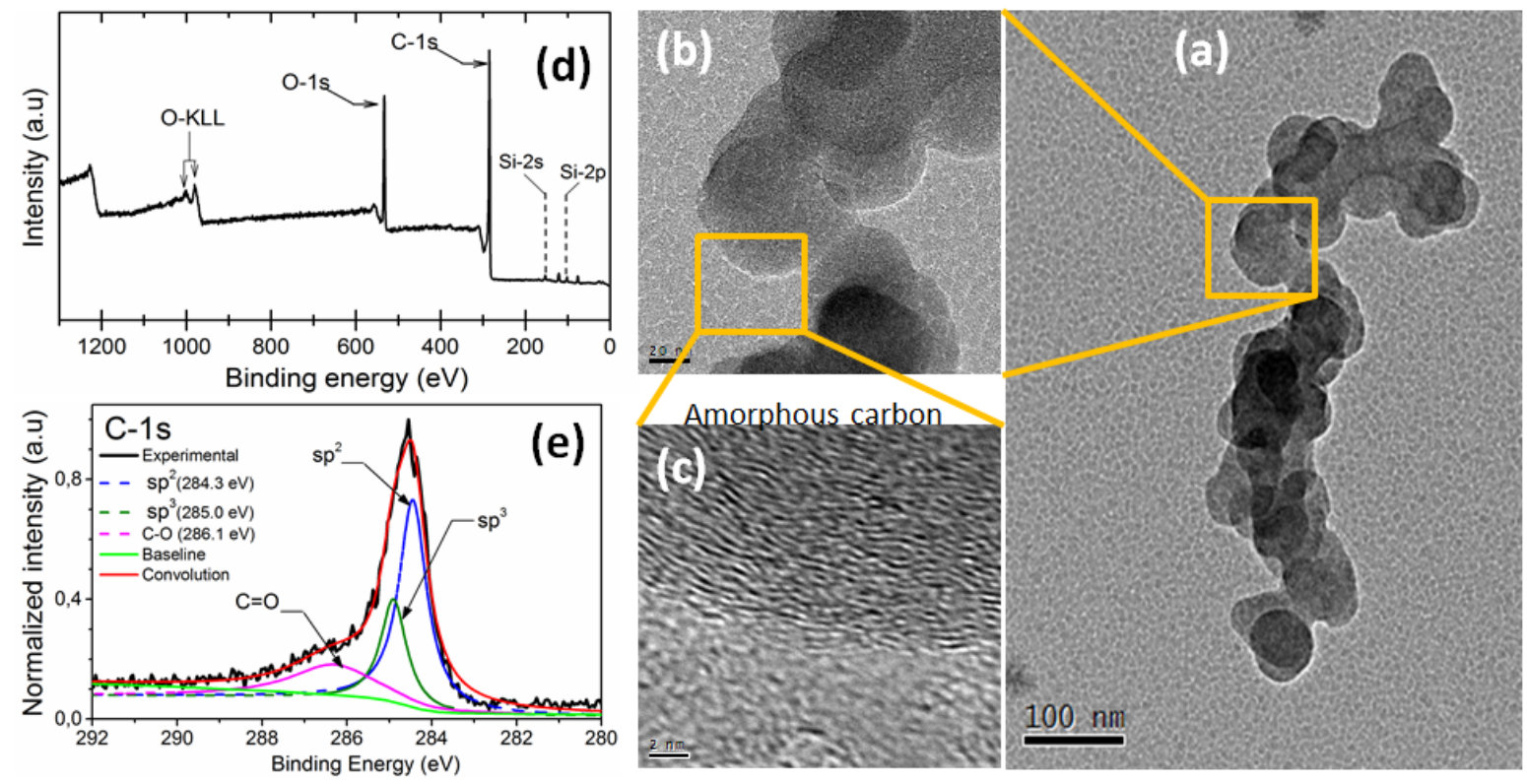

Figure 2. HRTEM images and XPS spectra. (a). an individual soot particle. (b). A segment (c). Higher magnification (amorphous carbon layer). (d). Survey XPS scan of soot particles emitted by the cook stove and (e). C-1s XPS spectra of soot particles. It was observed three important peaks: peak at $284.3 \mathrm{eV}$ of $\mathrm{sp}^{2}$ hybridization, peak at $285.0 \mathrm{eV}$. 